\title{
Nasal leprosy: an ancient disease not to be forgotten
}

\author{
Andrew C.G.J' ${ }^{1}$, Chong H.S \\ ${ }^{1}$ Dr. Andrew CGJ, ${ }^{2}$ Dr. Chong HS, all authors are affiliated with Otorhinolaryngology Department, Hospital Queen \\ Elizabeth, Kota Kinabalu, Sabah, Malaysia.
}

Address for Correspondence: Dr. Andrew Charles Gomez Junior, Otorhinolaryngology Department, Hospital Queen Elizabeth, Kota Kinabalu, Sabah, Malaysia. Email: aj06556@hotmail.com

\begin{abstract}
We are reporting a case of a gentleman referred to a tertiary care center for epistaxis associated with maggots in the nose and was found to have a nasal septal perforation. He underwent investigations with histopathologic analysis and skin slit smear to obtain a diagnosis. The patient received multidisciplinary management including endoscopic removal of the maggots and biopsies obtained from both the nasal septum and leg ulcers and subsequently anti leprosy medication.
\end{abstract}

Keywords: Nasal Septal, Septal Perforation, Leprosy

\section{Introduction}

Leprosy as a cause of nasal septal perforations has reduced over the past few decades. It should, however, be considered should preliminary investigations fail to indentify an etiological factor. We report a case of a gentleman who was referred to a tertiary care center for epistaxis associated with maggots in the nose who underwent investigations including a histopathological analysis and Polymerase chain reaction test to obtain a diagnosis of nasal leprosy.

\section{Case Report}

A 58-year-old gentleman, with no significant previous medical illness, was referred to a tertiary care center for evaluation of a 5 day history of multiple episodes of epistaxis associated with maggots coming out from both nostrils, right sided facial swelling and pain. Further history revealed the patient had also been experiencing bilateral nasal blockage and anosmia which worsened over the past 2 years. Review of systems revealed bilateral painless, non-healing, anterior shin ulcers, and a history of on and off low-grade fever for 2 years. Patient denied a history of trauma, loss of weight or appetite, nor did he have contact with a patient with pulmonary tuberculosis. There were no ear or throat symptoms. He denied a family history of malignancy or other communicable diseases. Patient was a non-smoker and did not consume alcohol. He worked as a rubber tapper.

On examination, patient had an average body habitus, not septic looking with good hydration. He was clinically pale. No cervical lymphnodes were palpable. He was noted to have a non-tender, erythematous right sided facial swelling just below the right orbit. Inspection of the nose was unremarkable. Anterior rhinoscopy revealed a maggot infested right nasal cavity. Naso endoscopy revealed multiple maggots occupying the right nasal cavity, eroded turbinates and a perforated septum. The nasopharynx and Fossa of Rossenmuller were normal. Examination of the oral cavity and a indirect laryngoscope revealed a normal hard palate with well defined white patches at the posterior oropharyngeal wall and a mildly swollen epiglottis and arythenoids. Both vocal cords were mobile with no phonation gap. There were no cranial nerve palsies. Multiple large ulcers with elevated violaceous edges and a well granulated base with yellowish exudates were noted. The distal lower limbs had scaly hyperkeratotic lesions. Examination of other systems were unremarkable.

\footnotetext{
Manuscript received $5^{\text {th }}$ October 2016

Reviewed: $16^{\text {th }}$ October 2016

Author Corrected: $26^{\text {th }}$ October 2016

Accepted for Publication $11^{\text {th }}$ November 2016
} 


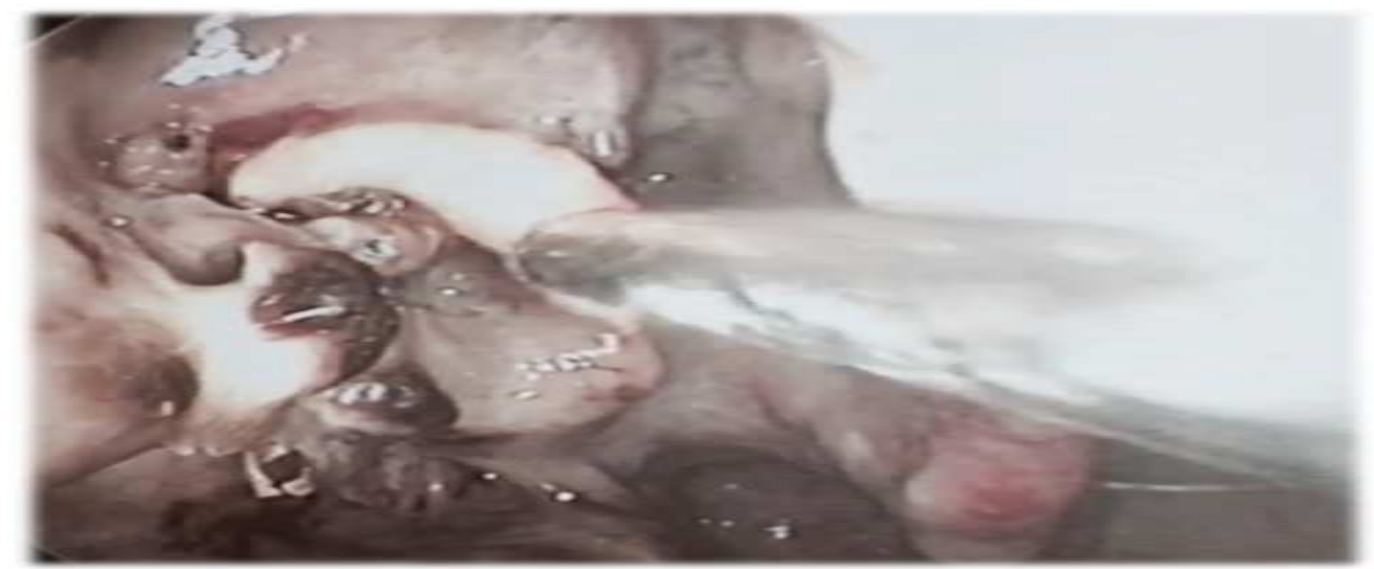

Figure-1: Showing the right nasal cavity upon presentation with multiple maggots seen within the lateral wall of the middle meatus.

A total of 75 maggots were removed endoscopically and daily turpentine nasal dressings were initiated. Biopsies from the septal mucosa revealed acute on chronic non specific infection. Debridement of the lower limb ulcers were done. After thorough investigations, a skin slit smear yielded a positive result. A diagnosis of Lucio Leprosy was made and confirmed by a PCR positive for mycobacterium leprae obtained form an ulcer edge biopsy. Anti leprosy medications were started. At the 2 week follow up visit, the general condition of the patient clinical improved. nasoendoscopy revealed a large nasal cavity with no maggots seen.

\section{Discussion}

Nasal septal perforations are among the commonest findings in midline destructive lesions [1]. The causes of perforations in the mucocatilagenous septum are well documented. Nasal leprosy, although previously a major cause of septal perforations, has reduced in prevalence tremendously, over the last few decades [2]. It should however be considered when preliminary investigations are inconclusive, while attempting to establish a cause for a septal perforation.

The etiology of septal perforations can be divided into infective and non infective causes [3]. Non-infective causes, contribute to majority of the cases [4]. Neoplastic, inflammatory, and trauma are among the non-infectious causes. Trauma including septal surgeries is the most prevalent cause [5]. These include perforations from an injury at the tissue level caused by nasal picking, prolonged use of nasogastric tubes, direct trauma from nasal fractures, foreign bodies, septal hematomes or septal surgeries, and injuries at a cellular level as seen in post radiated patients, long term use of nasal corticosteroids and nasal decongestants, chemical and industrial dusts(vapor chromium, copper salt, sulfuric acid, hydracholric acid, cement dust iron fillings, tar) and other aerosols used in agriculture [6]. Of the neoplastic conditions presenting with septal perforations, squamous cell carcinoma is the most common. Others include cryoglobulinemia and T-cell lymphomas [7]. Wegener's granulomatosis and sarcoidosis account for majority of the septal perforations with inflammatory conditions as an etiological factor [6]. These are often tested for in patients presenting with septal perforations.

Infective causes include bacterial, fungal and viral organisms. These include infective diseases such as HIV, Syphillis, Tuberculosis, rhinoscleroma, rinoesporidiose, paracoccidiodomycosis and septal abcesses [8]. In developing countries, leishmaniasis and leprosy still show a significant prevalence.

Leprosy is a debilitating disease which is caused by Microbacterium Leprae[3,9]. It is a chronic infection which causes granulomatous lesions [3]. It primarily invades peripheral nerve, small vessels and monocytes. These translate clinically to skin and nerve manifestations of the disease. With its predilection for cooler areas, the nose is often an area in which it grows.

Leprosy is disease whose prevalence has been dropped drastically over the past few decades [2]. In 2001 the World Health Assembly Resolution was intended to achieve the national elimination of leprosy, as targeted in December 2005. The 2012 report showed the global prevalence in 2011, as reported by 105 countries, was 219075 had reduced to 181941 in the beginning of 
2012 [2]. In South East Asia cases dropped as a whole from 8.75 to 0.64 cases per 100000 population. This was attributed to efforts by the national programmes with support from national and international partners. In Malaysia the incidence was shown to be 0.76 per 100000[2]. There are 5 types of clinical, histopathological and immunological classifications of the disease. These include tuberculoid, borderlinetuberculoid, borderline, borderline-lepromatous and lepromatous types [3]. Tuberculoid involves primarily the skin and nerves while lepromatous is more cartilaginous and skin involvement [10]. Nasal involvement as Barton reported in his review of 77 patients is at about 94\% [3]. These symptoms were reported to be in relation to the granulomatous lesions within the nasal cavity [3]. Early changes were said to include isolated nodules or plaques with mucous membrane thickening. Late changes included nasal obstruction, crusting and septal ulcerations leading to perforations. Rarely epistaxis occurred. The site of greatest involvement was the anterior inferior turbinate and the nasal septum.

Upon diagnosis, initiation of multidrug therapy, the nasal symptoms often improve rapidly alongside systemic symptoms [9]. The diagnosis and initiation of treatment should therefore be without delay. In saying that although a rare cause it is therefore a notably important diagnosis to consider in patients with septal perforations in which initial investigations are inconclusive.

\section{Conclusion}

As shown by this case, leprosy although a less common cause of septal perforations in this era, continues to still be a notably important diagnosis to consider in patients with septal perforations in which initial investigations are inconclusive.

\section{Acknowledgement}

Dr. Ahmad Nordin (MBBS, MS ORL-HNS[Mal])

Dr. Ong Cheng Ai (MBBS, MS ORL-HNS[Mal])
Dr. Halimuddin Bin Sawali (MBBS, MS ORL-HNS [Mal])

Dr. Yong Doh Jeing(MBBS, MS ORL-HNS [Mal], MRCS [Eng]).

Funding: Nil, Conflict of interest: None. Permission of IRB: Yes

\section{Reference}

1. Parker NP, Pearlman AN, Conley DB, Kern RC, Chandra RK. The dilemma of midline destructive lesions: a case series and diagnostic review. Am J Otolaryngol. 2010 Mar-Apr;31(2):104-9. doi: 10.1016/j. amjoto.2008.11.010. Epub 2009 Mar 27.

2.World Health Organization. Global leprosy situation, 2012.http://www.who.int/wer/2012/ wer8734. pdf?ua=1 (accessed 10 May 2015).

3. Barton RP. Clinical manifestation of leprous rhinitis. Ann Otol RhinolLaryngol.1976Jan-Feb;85(1Pt1):74-82.

4. Metzinger SE, Guerra AB. Diagnosing and treating Nasal Septal Perforations. Aesthet Surg J. 2005 SepOct; 25 (5):524-9. doi: 10.1016/j.asj.2005.06.002.

5. Brain DJ. Septo-rhinoplasty:closure of Septal Perforations. J Laryngol Otol. 1980May;94(5):495-505.

6. Fornazieri MA, Moreira JH, Pilan R, Voegels RL. Perforation of Nasal Septum: Etiology and Diagnosis. Int. Arch. Otorhinolaryngol. 2010;14(4):467-471

7. Baum ED, Boudousquie AC, Li S, Mirza N. Sarcoidosis with nasal obstruction and septal perforation. Ear Nose Throat J. 1998 Nov;77(11):896-8, 900-2.

8. RE M, Paolucci L, Romeu R, Mallardi V. Surgical treatment of nasal septalperforations: our experience. Acta Otorhinolaryngol Ital. 2006, 26(2):102-9.

9.Jacobson RR, Krahenbuhl JL. Leprosy. Lancet 1999; 353: 655-60.

10. Abulafia J, Vignale RA. Leprosy: pathogenesis updated. Int J Dermatol 1999;38:321-34.

\section{How to cite this article?}

Andrew C.G.J, Chong H.S. Nasal leprosy: an ancient disease not to be forgotten. Int J Med Res Rev 2016;4(11):19401942.doi:10.17511/ijmrr. 2016.i11.05. 